\title{
Olfactory subsystems associated with the necklace glomeruli in rodents
}

Arthur D. Zimmerman ${ }^{1,2,3}$ and Steven D. Munger ${ }^{1,2,3,4,5}$

${ }^{1}$ Department of Pharmacology and Therapeutics, University of Florida College of Medicine, PO Box 100267, Gainesville, FL 32610, USA

${ }^{2}$ Center for Smell and Taste, University of Florida, PO Box 100127, Gainesville, FL 32610, USA

${ }^{3}$ Training Program in Chemosensory Science, PO Box 100127, University of Florida, Gainesville, FL 32610, USA

${ }^{4}$ Department of Medicine, Division of Endocrinology, Diabetes and Metabolism, University of Florida College of Medicine, PO Box 100266, Gainesville, FL 32610, USA

${ }^{5}$ Correspondence to: steven.munger@ufl.edu 


\begin{abstract}
The necklace glomeruli are a loosely defined group of glomeruli encircling the caudal main olfactory bulb in rodents. Initially defined by the expression of various immunohistochemical markers, they are now better understood in the context of the specialized chemosensory neurons of the main olfactory epithelium and Grueneberg ganglion that innervate them. It has become clear that the necklace region of the rodent main olfactory bulb is composed of multiple distinct groups of glomeruli, defined at least in part by their afferent inputs. In this review, we will explore the necklace glomeruli and the chemosensory neurons that innervate them.
\end{abstract}

Keywords: GC-D; Trpc2; Grueneberg ganglion; cGMP; main olfactory bulb 


\section{INTRODUCTION}

The mammalian main olfactory bulb (MOB) is a three-layered cortical structure and the central nervous system target of peripheral chemosensory neurons within the main olfactory system (MOS). In mice, each olfactory sensory neuron (OSN) axon passes from its peripheral origin in the nose, through the skull, and along the surface of the MOB before entering and terminating in one of 2000 glomeruli - spherical neuropil near the pial surface - where they will synapse with second order projection neurons and local interneurons. While each glomerulus has the same basic structure and cellular components, each varies based on the type of OSN innervating it. In this review, we will focus on glomeruli in the most caudal aspects of the MOB, the so-called "necklace" glomeruli. Though they have been known for decades, the necklace glomeruli remain minimally studied and poorly understood. However, we have begun to better understand the chemosensory neurons that target the necklace glomeruli as well as the functions those sensory neurons subserve. This understanding provides us with important tools to investigate this obscure but important domain of the olfactory brain.

\section{OLFACTORY SUBSYSTEMS}

Mammalian olfactory systems can be divided into several subsystems based on the anatomical location of their sensory neurons, the type of olfactory receptors they express, the signaling mechanisms they employ to transduce chemosensory stimuli, the chemosensory stimuli they respond to, and the axonal targets of their sensory neurons to regions of the olfactory forebrain (Munger et al. 2009b). The principal division in rodents is between the main and accessory olfactory systems (Figure 1A). The accessory olfactory system (AOS) includes a distinct peripheral sensory structure, the vomeronasal organ, and a circumscribed target region in the olfactory forebrain, the accessory olfactory bulb (AOB). Three subpopulations of 
vomeronasal sensory neurons (VSNs) can be distinguished based on the family of chemosensory receptors they express: type 1 vomeronasal receptors (V1Rs), type 2 vomeronasal receptors (V2Rs), or formyl peptide-like receptors (FPRs). Each group of VSNs maintains a distinct projection pattern to the AOB.

The MOS includes the MOB as well as three distinct sensory organs: the main olfactory epithelium (MOE), the septal organ of Masera, and the Grueneberg ganglion (Figure 1A). In the rodent nasal cavity, the MOE covers the nasal septum in its most superior and posterior aspects, the nasal turbinates on each lateral wall, and the dorsal recesses that connect them. The MOE contains several distinct subpopulations of OSNs. These include canonical OSNs that express G protein-coupled odorant receptors (ORs) first described by Buck and Axel; OSNs expressing trace amine-associated receptors (TAARs); guanylyl cyclase-D (GC-D)-expressing OSNs (GC-D+ OSNs); and several populations of transient receptor potential (TRP)-channel expressing neurons. Each of the OSN subpopulations innervate the MOB. OSNs located within the septal organ, an anteriorly displaced patch of epithelium that is similar in composition to the MOE, also innervate the $\mathrm{MOB}$, as do chemosensory neurons found at the most anterior aspect of the nasal cavity within the Grueneberg ganglion.

The rodent olfactory bulb can be divided into several anatomical domains based on the molecular identity and anatomical origin of the chemosensory neurons that innervate them. For example, the anterior $A O B$ receives projections from $\mathrm{V} 1 \mathrm{R}$-expressing $\mathrm{VSN}$, while the posterior $A O B$ is innervated by VSNs expressing V2Rs (Figure 1A). The MOB contains even more subdivisions. OSNs within the septal organ primarily innervate glomeruli on the ventromedial aspect of the caudal MOB. Canonical OSNs expressing Class I ORs (which are most closely related to ORs found in fish) and TAAR-expressing OSNs from the MOE innervate adjacent regions of the dorsal MOB, while canonical MOE OSNs expressing Class II ORs innervate glomeruli along the lateral, medial and ventral surfaces (Figure 1B). The caudal-most aspects of the MOB comprise the "necklace" region, so named because early histochemical and 
immunohistochemical staining revealed a ring of glomeruli encircling the posterior MOB like beads on a chain (Figure 1C). This region contains necklace glomeruli innervated by several subpopulations of chemosensory neurons including GC-D+ OSNs from the MOE and septal organ, Trpc2+ OSNs from the MOE, and ciliated sensory neurons emerging from the Grueneberg ganglion (Figure 1D).

\section{THE NECKLACE GLOMERULI}

The necklace glomeruli have been differentially defined. The term was first coined by Shinoda and colleagues, who identified a small number of OSNs in the rat that were immunoreactive for human placental antigen X-P2 (PAX) and which converged on 7-9 glomeruli that ringed the caudal MOB (Shinoda et al. 1989). These glomeruli overlapped with a subset of "atypical" glomeruli that displayed acetylcholinesterase (AChE) reactivity (Shinoda et al. 1993; Zheng et al. 1987). Subsequent immunohistochemical studies with two monoclonal antibodies of unclear immunoreactivity - 2C6 and MAb213 - also labeled axons innervating subsets of glomeruli in the necklace region (Ring et al. 1997). However, while MAb213+ glomeruli were typically also $\mathrm{AChE}+, 2 \mathrm{C} 6+$ glomeruli were not. This suggests that the $2 \mathrm{C} 6$ and MAb213 antigens are found in two distinct groups of OSNs that target glomeruli of the necklace region. Ring and colleagues also suggest that the $\mathrm{PAX}+/ \mathrm{AChE}+$ glomeruli are a subset of the MAb213+/AChE+ glomeruli. The antigens recognized by the PAX, 2C6 and MAb213 antibodies were not restricted to OSN axons, but were also abundant in the somata and dendrites of those neurons. Immunoreactive OSNs were typically found in the dorsal and lateral recesses (a.k.a., cul-de-sacs) between the turbinates. Although no colocalization studies were done, it does appear that 2C6+ and MAb213+ OSNs are distinct subpopulations (Ring et al. 1997), a finding consistent with the lack of overlap in the MOB. Together, these studies indicate that glomeruli in 
the necklace region are molecularly diverse. Therefore, it is probably best to think of this MOB domain as containing more than one chain of necklace glomeruli.

Studies have identified other subpopulations of chemosensory neurons innervating glomeruli in the necklace region. Approximately 15 glomeruli in the necklace region are innervated by OSNs expressing the phosphodiesterase isoform Pde2A (Juilfs et al. 1997). In the MOE, Pde2A colocalizes with the atypical olfactory receptor guanylyl cyclase type D (GC-D) (Juilfs et al. 1997), indicating that this OSN type innervates at least a subset of necklace glomeruli. OSNs expressing the transient receptor potential channel Trpc2 innervate two ventral MOB glomeruli within, or adjacent to, the necklace. And neurons of the Grüneberg ganglia innervate dorsomedial necklace glomeruli (Fuss et al. 2005) that are closely apposed to, but distinct from, those innervated by GC-D+ OSNs (Matsuo et al. 2012) (Figure 1D). We will focus on these three sensory neuron populations for the rest of this review.

\section{CHEMOSENSORY NEURONS INNERVATING THE NECKLACE GLOMERULI}

\section{GC-D-expressing olfactory sensory neurons}

GC-D+ OSNs were first identified in the mouse by their expression of the type $D$ isoform of the receptor guanylyl cyclase family (Fulle et al. 1995; Kuhn 2009). They are ciliated, bipolar neurons similar in morphology to canonical OSNs (Fulle et al. 1995). Surprisingly, they do not express olfactory marker protein (OMP) (Cockerham et al. 2009), broadly considered a conserved marker for vertebrate OSNs. GC-D+ OSNs are scattered throughout the rodent MOE but represent less than $1 \%$ of OSNs. They are produced throughout the lifespan, and terminal maturation coincides with the expression of GC-D, MS4A putative chemoreceptors (Greer et al. 2016), and the neuropeptide CART (cocaine and amphetamine regulated transcript) (Bloom et al. 2020). Most GC-D+ OSNs are found singly or in clusters within the dorsal recesses of the 
ectoturbinates, but they can also be found on the endoturbinates and the septum and in the septal organ (Fulle et al. 1995; Hu et al. 2007; Ma et al. 2003). The axons of GC-D+ OSNs project through the cribiform plate of the skull and synapse in $\sim 15$ necklace glomeruli within the caudal MOB (Juilfs et al. 1997; Leinders-Zufall et al. 2007; Walz et al. 2007). While GC-D+ OSN axons have innervated the MOB by postnatal day one, their target glomeruli do not appear for a few days more (Walz et al. 2007).

Canonical MOB glomeruli receive homogenous input from OSNs expressing the same OR. By contrast, individual necklace glomeruli innervated by GC-D+ OSNs (GC-D+ necklace glomeruli) are also innervated by as second, noncanonical OSN subtype that is OMP+ but PDE4A- (Cockerham et al. 2009). The specific identity of this other OSN population remains unknown. However, the heterogeneous afferent input would seem to preclude the combinatorial coding scheme observed in the canonical MOS. GC-D+ OSN-innervated necklace glomeruli are tightly integrated into MOB circuitry, as both neuronal tracing and functional imaging studies have shown that interneurons associated with individual GC-D+ necklace glomeruli have extensive interglomerular connectivity with both other necklace and non-necklace glomeruli (Cockerham et al. 2009). However, the implications for the intrabulbar connections for odor processing by GC-D+ necklace glomeruli remain unclear.

Canonical OSNs express proteins associated with a cAMP-mediated olfactory transduction cascade, including the G protein subunit $\mathrm{Ga}_{\text {olf }}$, type III adenylyl cyclase (ACIII), the phosphodiesterase isoforms PDE1C or PDE4A, and the cyclic nucleotide-gated (CNG) channel subunits Cnga2, Cnga3 or Cngab1b (reviewed in (Munger et al. 2009a)). Indeed, while Cnga2 null mice show a loss of afferent activity to canonical glomeruli, it is retained to Pde2A+ glomeruli (Baker et al. 1999). Instead, GC-D+ OSNs express proteins implicated in cGMPmediated signaling, including the cGMP-stimulated phosphodiesterase Pde2A, the $\mathrm{Ca}^{2+}-$ calmodulin stimulated PDE isoform PDE1A and the cGMP-specific CNG channel subunits 
Cnga3 and Cngb3, in addition to GC-D itself (Bloom et al. 2020; Fulle et al. 1995; Hu et al. 2007; Huang et al. 2018; Juilfs et al. 1997). Treatment with the cyclic nucleotide analog 8bromo-cGMP increases action potential firing in GC-D+ OSNs (Leinders-Zufall et al. 2007), while pharmacologic inhibition or genetic deletion of Cnga3 renders the cells incapable of activation by chemosensory stimuli (Leinders-Zufall et al. 2007; Munger et al. 2010).

GC-D+ OSNs respond to a limited repertoire of diverse chemosensory stimuli. Two guanylin family peptides, guanylin and uroguanylin, are highly potent and specific stimuli for these cells. These peptides are also excreted in urine and feces, two rich sources of semiochemicals for rodents, and are thus available as chemosignals in natural environments. Guanylin and uroguanylin activate the MOE of wildtype mice at $K_{1 / 2}$ values as low as $66 \mathrm{pM}$, but responses are completely absent in the MOE of either Gucy2d or Cnga3 null mice (LeindersZufall et al. 2007). However, individual GC-D+ OSNs do not show identical response profiles to the guanylin peptides: approximately half of these cells respond to either uroguanylin or guanylin alone, while the remaining GC-D+ OSNs respond to both peptides (Leinders-Zufall et al. 2007). The basis of these functional differences is not known. It is also unclear if these functionally disparate GC-D+ OSN subpopulations project to different subsets of necklace glomeruli. GC-D+ OSNs also respond to carbon disulfide $\left(\mathrm{CS}_{2}\right)$ (Munger et al. 2010), a volatile semiochemical that is found in mammalian breath (Galef et al. 1988). CS 2 activation of the MOE at submicromolar concentrations is dependent on GC-D and Cnga3, and identified neurons in Gucy2d null mice are unresponsive to this compound (Munger et al. 2010). Carbon dioxide $\left(\mathrm{CO}_{2}\right)$ can also activate GC-D+ OSNs (Hu et al. 2007), albeit only at concentrations greater than 7 mM (Munger et al. 2010).

The GC-D protein itself is likely the principal chemoreceptor in these cells. Many members of this protein family function as peptide receptors, and the closely related mammalian GC-C is also activated by guanylin and uroguanylin (Kuhn 2009). One in vitro study directly 
supports the model that GC-D is similarly a receptor for uroguanylin (Duda and Sharma 2008). However, more systematic studies were initially hampered by a surprising characteristic of GCD: the enzymatic activity of this protein is activated by intracellular bicarbonate (Guo et al. 2009; Sun et al. 2009), and thus at maximal activity when expressed in heterologous cells cultured in elevated $\mathrm{CO}_{2}$. Interestingly, this bicarbonate sensitivity is likely the mechanism by which both $\mathrm{CS}_{2}$ and $\mathrm{CO}_{2}$ can activate GC-D+ OSNs. Indeed, inhibition of carbonic anhydrase 2 (Car2) expressed in GC-D+ OSNs nearly abolishes $\mathrm{CS}_{2}$-dependent responses in these cells, and similar results are seen in Car2-deficient mice (Munger et al. 2010). While Car2-deficient mice also fail to avoid elevated environmental $\mathrm{CO}_{2}(\mathrm{Hu}$ et al. 2007), the real-world relevance of this GC-D+ OSN-mediated $\mathrm{CO}_{2}$ avoidance is unclear given the high $\mathrm{CO}_{2}$ concentrations needed to activate these cells.

Members of another protein family have been proposed to play a role as chemosensory receptors in GC-D+ OSNs, the membrane-spanning 4A (MS4A) proteins (Greer et al. 2016). MS4A proteins are four-pass transmembrane proteins, many of which have are expressed in leukocytes where they play a role in cell activation, growth and development (Eon Kuek et al. 2016). In the MOE, MS4A proteins are expressed in the distal dendrites of GC-D+ OSNs, though whether they are localized to dendritic cilia (the principal site of olfactory transduction) is less clear. In both in vitro and ex vivo experiments, MS4As confer responses to ethologically relevant ligands including pheromones and fatty acids with half maximal effective concentrations (EC50) values in the micromolar range, show no functional implications of these MS4A proteins as receptors and fail to show ciliary localization of the MS4A proteins. Future work should clarify the roles of MS4As in GC-D+ OSNs, including whether there is intracellular crosstalk with the GC-D-mediated sensory transduction cascade.

GC-D+ OSNs play a central role a type of odor-driven associative learning known as the social transmission of food preference (STFP) (Munger et al. 2010). First described decades 
ago (Galef 1985; Galef and Wigmore 1983; Posadas-Andrews and Roper 1983), STFPs occur when a recipient rodent (the observer) simultaneously encounters a general odor - such as a food odor - and a relevant semiochemical - such as $\mathrm{CS}_{2}$ (Galef et al. 1988) - from a conspecific (the demonstrator). When the observer rodent is presented with a choice of two otherwise identical foods that contain either the demonstrated odor or a novel odor, it will display a strong preference for food containing the demonstrated odor. GC-D+ OSNs are required for STFP acquisition: Gucy2d and Cnga3 null mice, as well as mice receiving an intranasal injection of a carbonic anhydrase inhibitor, fail to acquire an STFP from either a live demonstrator or from a surrogate demonstrator presenting the general odor plus a GC-D+ OSN stimulus ( $\mathrm{CS}_{2}$, guanylin or uroguanylin) (Arakawa et al. 2013; Kelliher and Munger 2015; Munger et al. 2010). This preference acquisition does not require either a food choice or consummatory behavior, as mice will exhibit a GC-D-dependent odor preference when undergoing the same conditioning paradigms (Zimmerman et al. 2020). These GC-D-dependent odor preferences can be acquired by neonates and are maintained for weeks (Zimmerman et al. 2020). GC-D-dependent preferences can even be acquired for odors to which mice are made conditionally averse, suggesting that GC-D+ OSNs have a privileged role in odor learning (Zimmerman et al. 2020).

\section{Trpc2-expressing olfactory sensory neurons}

Although broadly expressed in chemosensory neurons of the vomeronasal organ, transient receptor potential channel 2 (Trpc2) is also found in a small number of OSNs (Trpc2+ OSNs) of the MOE (Liman et al. 1999). Trpc2+ OSNs are ciliated neurons that express the ion channel subunit $\mathrm{Cnga2}$ and the $\mathrm{G}$ protein subunit $\mathrm{Ga}_{\circ}$ (Choi et al. 2016; Omura and Mombaerts 2014). The Trpc2+ OSNs can be further divided into two subtypes: Type A, which expresses ACIII, and Type B, which does not. Approximately one-third of Trpc2+ Type A cells coexpress 
canonical ORs Olfr68 and Olfr69. By contrast, Trpc2+ Type B OSNs may rely on a cGMP signaling cascade. They express the soluble guanylyl cyclase Gucy1b2 as well as phosphodiesterases Pde1c, Pde4a and Pde6d (Omura and Mombaerts 2015; Saraiva et al. 2015).

A functional role for Trpc2+ Type A OSNs has not been described, but their expression of two ORs and the cAMP-producing enzyme ACIII suggests that they may transduce olfactory stimuli similarly to canonical OSNs. By contrast, mouse Trpc2+ Type B OSNs have been implicated in the detection low oxygen levels (Bleymehl et al. 2016). Low oxygen levels generate a rapid and non-adaptive $\mathrm{Ca}^{2+}$ response in Trpc2+ Type $\mathrm{B}$, but not Type $\mathrm{A}$, OSNs that is abolished in both Gucy1b2 and Trpc2 null mice. However, Cnga2 null mice showed wildtype responses, indicating that Trpc2 but not $\mathrm{Cnga} 2$ is the critical ion channel in for low oxygen responses in Type B cells. Low oxygen also produced a Gucy1b2-dependent increase in cFos+ cells around glomeruli innervated by Trpc2+ OSNs as well as a Gucy1b2- and Trpc2-dependent behavioral aversion to low environmental oxygen.

\section{Grueneberg ganglion neurons}

The Grueneberg ganglia (GG), bilateral clusters of neurons (GGNs) at the most anterior aspect of the nasal cavity, were first described nearly 50 years ago (Gruneberg 1973). The GG were "rediscovered" in the mouse many years later when this patch of OMP+ neurons were recognized by several groups nearly simultaneously (Fleischer et al. 2006a; Fuss et al. 2005; Koos and Fraser 2005; Roppolo et al. 2006; Storan and Key 2006). A subsequent study found the GG in rats, gerbils and hamsters, as well, albeit with some morphological and physiological variations(Brechbuhl et al. 2014). GGNs lie within a fibroblast meshwork between the nasal septum and a keratinized epithelium (Fleischer et al. 2006a; Fuss et al. 2005; Roppolo et al. 
2006; Storan and Key 2006). While GGNs do not have prominent dendrites or microvilli, and they do not directly access the nasal lumen, they do possess numerous cilia that are speculated to play a role in sensory transduction (Breer et al. 2006). Glial cells wrap around GGNs, entrapping the cilia within the ganglion. Initially thought to be associated with the nervus terminalis (Gruneberg 1973), later studies showed that GGNs project to the caudal MOB. GGNs fasciculate into a single or a few nerve bundles that project to about 10 necklace glomeruli (Fuss et al. 2005; Koos and Fraser 2005; Roppolo et al. 2006). These glomeruli are distinct from those innervated by GC-D+ OSNs (Matsuo et al. 2012) (Figure 1D).

It is clear that GGNs are heterogeneous in their molecular signatures. One subpopulation of GGNs express the type 2 vomeronasal receptor V2r83 (Fleischer et al. 2006b). Another expresses members of the TAAR family, though this expression seems restricted to late embryonic and neonatal time points (Fleischer et al. 2007). Numerous signal transduction proteins are expressed in GGNs, including $\mathrm{Ga}_{\circ}, \mathrm{Ga}_{\mathrm{i} 2}, \mathrm{Ga}_{\text {olf }}$ and ACIII (Fleischer et al. 2006b). Of particular note, many GGNs express components of a cGMP signaling cascade (Fleischer et al. 2009; Liu et al. 2009; Mamasuew et al. 2011; Schmid et al. 2010). V2r83+ GGNs coexpress transmembrane guanylyl cyclase subtype G (GC-G) (Fleischer et al. 2009). Pde2a and Cnga3 are also expressed in GGNs, but not GC-D or Car2 (Fleischer et al. 2009; Liu et al. 2009; Schmid et al. 2010). The neuropeptide CART is not expressed in GGNs (Huang et al. 2018).

While no peptide ligands have been identified for GC-G (unlike GC-D), this protein is responsive to intracellular bicarbonate (Chao et al. 2010) and to cold temperatures (Chao et al. 2015). This latter function is consistent with a thermosensory role for GGNs. Indeed, multiple studies find that GGNs function as cold sensors (Mamasuew et al. 2008; Schmid et al. 2010). While, the exact mechanism by which these cells transduce cold temperature is unclear, it does appear to be independent of Cnga3. Furthermore, at least one study found that thermosensory responses are more pronounced in juvenile mice (Mamasuew et al. 2008). 
Despite the fact that GGNs are not directly exposed to the nasal lumen, there is good evidence that they also function as chemosensors, particularly for different types of semiochemicals. Alarm pheromones - a poorly defined chemosignal that is produced when animals are stressed or injured - will induce responses in GGNs (Brechbühl et al. 2008). Additionally, GGN axotomy will abolish alarm pheromone-dependent freezing behaviors (Kikusui et al. 2001). A number of monomolecular putative semiochemicals have also been linked to activation of the GG. These include the predator odorant 2-propyl thietane (2-PT) (Brechbuhl et al. 2013; Perez-Gomez et al. 2015), some pyridine analogs (Brechbuhl et al. 2015), 2-sec-butyl-4,5-dihyrothiazole (SBT) (Brechbuhl et al. 2013) and 2,3-dimethylpyrazine (Hanke et al. 2013; Mamasuew et al. 2011). Together with the responses to cold temperatures, these findings suggest that the GG is important for avoiding potential dangers. Intriguingly, a recent study indicates that activation of the GG by predator odors in the context of food choices can impact those choices and even modify GC-D-dependent preferences (Brechbuhl et al. 2020).

\section{TARGETS OF THE NECKLACE GLOMERULI}

Compared to the afferent inputs to the necklace glomeruli, relatively little is known about their efferent targets in other areas of the brain. Activation of either GC-D+ OSNs or GGNs during behavioral exposure to their cognate stimuli leads to activation of subsets of necklace glomeruli, as assessed by an increase in nearby cFos-immunopositive juxtaglomerular cells (Perez-Gomez et al. 2015; Zimmerman and Munger unpublished). The ventral subiculum of the hippocampus is activated during acquisition of an STFP (Munger et al. 2010; Ross and Eichenbaum 2006), but the (likely) multisynaptic connections linking this region to the necklace glomeruli is unknown. Unpublished neuronal tracing studies from our group indicate that projection neurons associated with GC-D+ necklace glomeruli send axons to regions of the 
olfactory peduncle including the anterior olfactory nucleus (AON) and tenia tecta. Two new lines of evidence support a role for the AON in STFP acquisition. Disruption of AON projections to the MOB impair the acquisition, but not the recall, of an STFP (Wang et al. 2020). Consistent with this, we have found that certain AON subdivisions show a GC-D-dependent increase in cFos+ cells after the acquisition phase of an STFP. Thus, it appears that the AON is a prime candidate for a key role in this odor-mediated social learning.

\section{CONCLUSIONS}

While the necklace glomeruli, their afferent inputs and their efferent targets remain poorly understood - at least compared to the components of the canonical main olfactory system progress is being made. Critically, powerful molecular genetic tools, specific chemostimuli and distinct odor-mediated behaviors have been developed or identified for each of the three subsystems most clearly associated with the necklace region. It is now important to use these tools to understand how the olfactory information carried by each of these subsystems is processed in the brain. Of particular interest will be efforts to illuminate the neural mechanisms mediating interactions between these and with other subsystems, interactions that are critical if animals are to form a complete picture of, and develop appropriate behavioral responses to, a complex chemosensory world. 


\section{ACKNOWLEDGEMENTS}

This work was supported by grants from the National Institute on Deafness and Other Communication Disorders: R01 DC005633 and T32 DC015994.

\section{ETHICS STATEMENT}

No human or animal studies were conducted for this paper. 


\section{A}
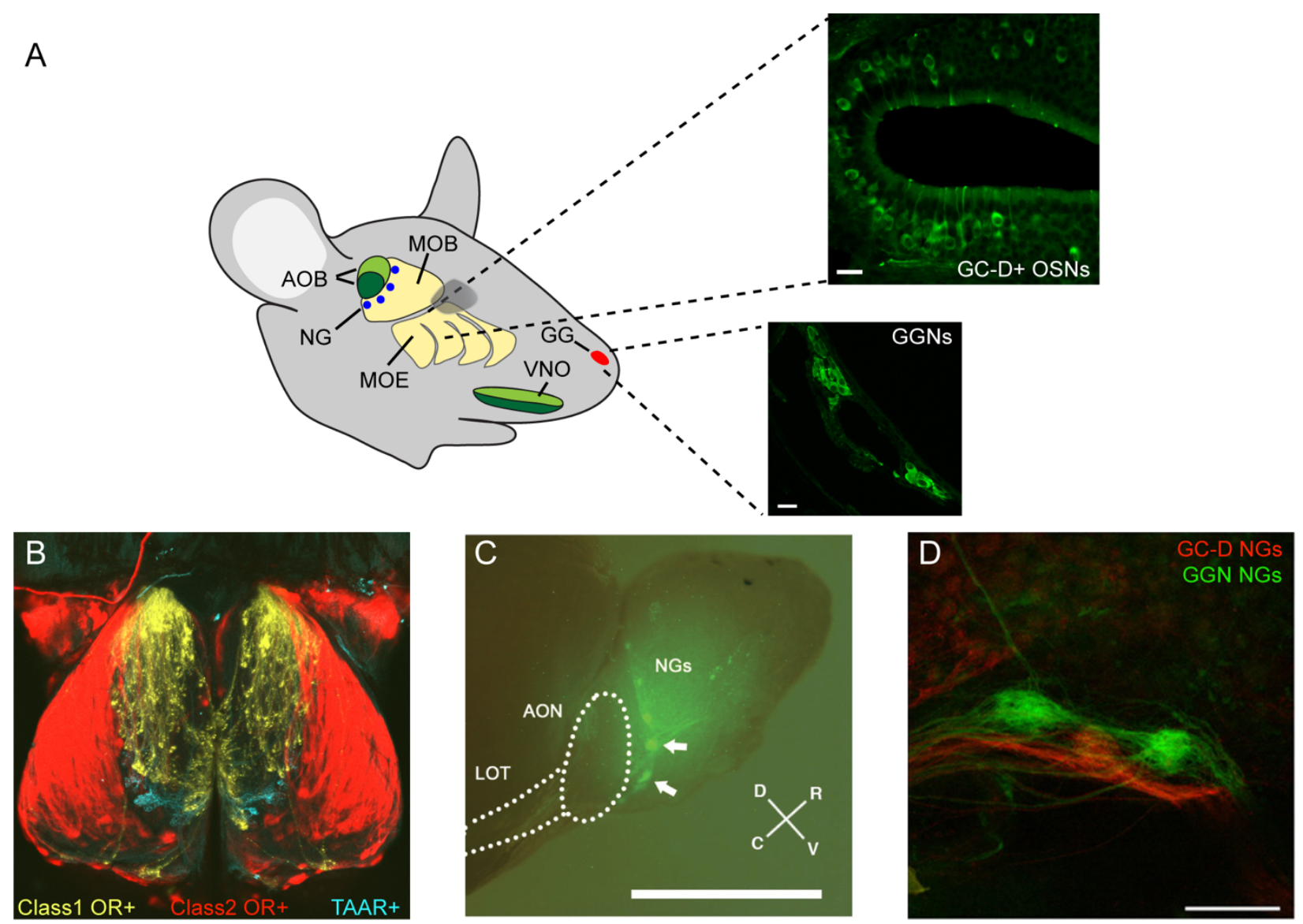

Figure 1: (A) Schematic illustrating the mouse olfactory system. VNO, vomeronasal organ (apical region, light green; basal region, dark green); GG, Grueneberg ganglion (red); MOE, main olfactory epithelium (yellow); MOB, main olfactory bulb (yellow); NG, necklace glomeruli (blue circles); $\mathrm{AOB}$, accessory olfactory bulb (anterior region, light green; posterior region, dark green). Blowouts show confocal micrographs of (top) GC-D+ OSNs in a dorsal recess of the MOE, and (bottom) GG neurons (GGNs) within the GG. Modified from (Munger et al. 2010), with permission. (B) Whole mount mouse olfactory bulbs (dorsal view; rostral towards top) showing how the glomerular targets of OSNs expressing different classes of olfactory receptor - including canonical odorant receptors (ORs: Class I member, yellow; Class II member, red) or trace amine-associated receptors (TAARs; cyan) - are segregated in the MOB. OSNs were labeled with different genetically encoded fluorescent reporters. Modified from (Pacifico et al. 2012), with permission. (C) Necklace glomeruli innervated by axons of GC-D+ olfactory sensory neurons (green; arrows for examples of the necklace glomeruli). Lateral view of the olfactory bulb and other forebrain areas of a Gucy2d-EGFP reporter mouse, including the anterior olfactory nucleus (AON) and lateral olfactory tract (LOT). R, rostral; C, caudal; D, dorsal; V, ventral. Modified from (Uytingco et al. 2016), with permission. (D) Confocal micrograph of necklace glomeruli innervated by GC-D+ OSNs (red) or GGNs (green). Modified from (Matsuo et al. 2012), with permission. 


\section{REFERENCES}

Arakawa H, Kelliher KR, Zufall F, Munger SD. 2013. The receptor guanylyl cyclase type D (GCD) ligand uroguanylin promotes the acquisition of food preferences in mice. Chem Senses 38: 391-397.

Baker H, Cummings DM, Munger SD, Margolis JW, Franzen L, Reed RR, Margolis FL. 1999. Targeted deletion of a cyclic nucleotide-gated channel subunit (OCNC1): biochemical and morphological consequences in adult mice. J Neurosci 19: 9313-9321.

Bleymehl K, Perez-Gomez A, Omura M, Moreno-Perez A, Macias D, Bai Z, Johnson RS, Leinders-Zufall T, Zufall F, Mombaerts P. 2016. A Sensor for Low Environmental Oxygen in the Mouse Main Olfactory Epithelium. Neuron 92: 1196-1203.

Bloom ML, Johnston LB, Datta SR. 2020. Renewal and Differentiation of GCD Necklace Olfactory Sensory Neurons. Chem Senses 45: 333-346.

Brechbuhl J, de Valliere A, Wood D, Nenniger Tosato M, Broillet MC. 2020. The Grueneberg ganglion controls odor-driven food choices in mice under threat. Commun Biol 3: 533.

Brechbühl J, Klaey M, Broillet MC. 2008. Grueneberg ganglion cells mediate alarm pheromone detection in mice. Science 321: 1092-1095.

Brechbuhl J, Klaey M, Moine F, Bovay E, Hurni N, Nenniger-Tosato M, Broillet MC. 2014. Morphological and physiological species-dependent characteristics of the rodent Grueneberg ganglion. Front Neuroanat 8: 87.

Brechbuhl J, Moine F, Klaey M, Nenniger-Tosato M, Hurni N, Sporkert F, Giroud C, Broillet MC. 2013. Mouse alarm pheromone shares structural similarity with predator scents. Proc Natl Acad Sci U S A 110: 4762-4767.

Brechbuhl J, Moine F, Tosato MN, Sporkert F, Broillet MC. 2015. Identification of pyridine analogs as new predator-derived kairomones. Front Neurosci 9: 253.

Breer H, Fleischer J, Strotmann J. 2006. The sense of smell: multiple olfactory subsystems. Cell Mol Life Sci 63: 1465-1475.

Chao YC, Chen CC, Lin YC, Breer H, Fleischer J, Yang RB. 2015. Receptor guanylyl cyclase-G is a novel thermosensory protein activated by cool temperatures. EMBO J 34: 294-306.

Chao YC, Cheng CJ, Hsieh HT, Lin CC, Chen CC, Yang RB. 2010. Guanylate cyclase-G, expressed in the Grueneberg ganglion olfactory subsystem, is activated by bicarbonate. Biochem J 432: 267-273.

Choi JM, Kim SS, Choi Cl, Cha HL, Oh HH, Ghil S, Lee YD, Birnbaumer L, Suh-Kim H. 2016. Development of the main olfactory system and main olfactory epithelium-dependent male mating behavior are altered in Go-deficient mice. Proc Natl Acad Sci U S A 113: 1097410979.

Cockerham RE, Puche AC, Munger SD. 2009. Heterogeneous sensory innervation and extensive intrabulbar connections of olfactory necklace glomeruli. PLoS ONE 4: e4657.

Duda T, Sharma RK. 2008. ONE-GC membrane guanylate cyclase, a trimodal odorant signal transducer. Biochem Biophys Res Commun 367: 440-445.

Eon Kuek L, Leffler M, Mackay GA, Hulett MD. 2016. The MS4A family: counting past 1, 2 and 3. Immunol Cell Biol 94: 11-23.

Fleischer J, Hass N, Schwarzenbacher K, Besser S, Breer H. 2006a. A novel population of neuronal cells expressing the olfactory marker protein (OMP) in the anterior/dorsal region of the nasal cavity. Histochem Cell Biol 125: 337-349.

Fleischer J, Mamasuew K, Breer H. 2009. Expression of cGMP signaling elements in the Grueneberg ganglion. Histochem Cell Biol 131: 75-88.

Fleischer J, Schwarzenbacher K, Besser S, Hass N, Breer H. 2006b. Olfactory receptors and signalling elements in the Grueneberg ganglion. J Neurochem 98: 543-554. 
Fleischer J, Schwarzenbacher K, Breer H. 2007. Expression of trace amine-associated receptors in the Grueneberg ganglion. Chem Senses 32: 623-631.

Fulle HJ, Vassar R, Foster DC, Yang RB, Axel R, Garbers DL. 1995. A receptor guanylyl cyclase expressed specifically in olfactory sensory neurons. Proc Natl Acad Sci U S A 92: 3571-3575.

Fuss SH, Omura M, Mombaerts P. 2005. The Grueneberg ganglion of the mouse projects axons to glomeruli in the olfactory bulb. Eur J Neurosci 22: 2649-2654.

Galef B. 1985. Social learning in wild Norway rats. In: Johnston T, Pietrewicz A, (eds.), Issues in the Ecological Study of Learning. Hillsdale, NJ: Lawrence Erlbaum Associates. p. 143-166.

Galef B, Wigmore S. 1983. Transfer of information concerning distant foods: a laboratory investigation of the 'information-centre' hypothesis. Animal Behaviour 31: 748-758.

Galef BG, Jr., Mason JR, Preti G, Bean NJ. 1988. Carbon disulfide: a semiochemical mediating socially-induced diet choice in rats. Physiol Behav 42: 119-124.

Greer PL, Bear DM, Lassance JM, Bloom ML, Tsukahara T, Pashkovski SL, Masuda FK, Nowlan AC, Kirchner R, Hoekstra HE, Datta SR. 2016. A Family of non-GPCR Chemosensors Defines an Alternative Logic for Mammalian Olfaction. Cell 165: 1734-1748.

Gruneberg H. 1973. A ganglion probably belonging to the N. terminalis system in the nasal mucosa of the mouse. Z Anat Entwicklungsgesch 140: 39-52.

Guo D, Zhang JJ, Huang XY. 2009. Stimulation of guanylyl cyclase-D by bicarbonate. Biochemistry 48: 4417-4422.

Hanke W, Mamasuew K, Biel M, Yang RB, Fleischer J. 2013. Odorant-evoked electrical responses in Grueneberg ganglion neurons rely on cGMP-associated signaling proteins. Neurosci Lett 539: 38-42.

Hu J, Zhong C, Ding C, Chi Q, Walz A, Mombaerts P, Matsunami H, Luo M. 2007. Detection of near-atmospheric concentrations of $\mathrm{CO} 2$ by an olfactory subsystem in the mouse. Science 317: 953-957.

Huang Z, Zimmerman AD, Munger SD. 2018. Unique molecular markers for GC-D-expressing olfactory sensory neurons and chemosensory neurons of the Grueneberg ganglion. bioRxiv, https://doi.org/10.1101/346502. Cold Spring Harbor Laboratory.

Juilfs DM, Fulle HJ, Zhao AZ, Houslay MD, Garbers DL, Beavo JA. 1997. A subset of olfactory neurons that selectively express cGMP-stimulated phosphodiesterase (PDE2) and guanylyl cyclase-D define a unique olfactory signal transduction pathway. Proc Natl Acad Sci U S A 94: 3388-3395.

Kelliher KR, Munger SD. 2015. Chemostimuli for guanylyl cyclase-D-expressing olfactory sensory neurons promote the acquisition of preferences for foods adulterated with the rodenticide warfarin. Front Neurosci 9: 262.

Kikusui T, Takigami S, Takeuchi Y, Mori Y. 2001. Alarm pheromone enhances stress-induced hyperthermia in rats. Physiol Behav 72: 45-50.

Koos DS, Fraser SE. 2005. The Grueneberg ganglion projects to the olfactory bulb. Neuroreport 16: 1929-1932.

Kuhn M. 2009. Function and dysfunction of Mammalian membrane guanylyl cyclase receptors: lessons from genetic mouse models and implications for human diseases. Handbook of experimental pharmacology: 47-69.

Leinders-Zufall T, Cockerham RE, Michalakis S, Biel M, Garbers DL, Reed RR, Zufall F, Munger SD. 2007. Contribution of the receptor guanylyl cyclase GC-D to chemosensory function in the olfactory epithelium. Proc Natl Acad Sci U S A 104: 14507-14512.

Liman ER, Corey DP, Dulac C. 1999. TRP2: a candidate transduction channel for mammalian pheromone sensory signaling. Proc Natl Acad Sci U S A 96: 5791-5796.

Liu CY, Fraser SE, Koos DS. 2009. Grueneberg ganglion olfactory subsystem employs a cGMP signaling pathway. J Comp Neurol 516: 36-48. 
Ma M, Grosmaitre X, Iwema CL, Baker H, Greer CA, Shepherd GM. 2003. Olfactory signal transduction in the mouse septal organ. J Neurosci 23: 317-324.

Mamasuew K, Breer H, Fleischer J. 2008. Grueneberg ganglion neurons respond to cool ambient temperatures. Eur J Neurosci 28: 1775-1785.

Mamasuew K, Hofmann N, Kretzschmann V, Biel M, Yang RB, Breer H, Fleischer J. 2011. Chemo- and thermosensory responsiveness of Grueneberg ganglion neurons relies on cyclic guanosine monophosphate signaling elements. Neurosignals 19: 198-209.

Matsuo T, Rossier DA, Kan C, Rodriguez I. 2012. The wiring of Grueneberg ganglion axons is dependent on neuropilin 1. Development 139: 2783-2791.

Munger SD, Leinders-Zufall T, McDougall LM, Cockerham RE, Schmid A, Wandernoth P, Wennemuth G, Biel M, Zufall F, Kelliher KR. 2010. An olfactory subsystem that detects carbon disulfide and mediates food-related social learning. Curr Biol 20: 1438-1444.

Munger SD, Leinders-Zufall T, Zufall F. 2009a. Subsystem organization of the mammalian sense of smell. Annu Rev Physiol 71: 115-140.

Munger SD, Leinders-Zufall T, Zufall F. 2009b. Subsystem organization of the mammalian sense of smell. Annu Rev Physiol 71: 115-140.

Omura M, Mombaerts P. 2014. Trpc2-expressing sensory neurons in the main olfactory epithelium of the mouse. Cell Rep 8: 583-595.

Omura M, Mombaerts P. 2015. Trpc2-expressing sensory neurons in the mouse main olfactory epithelium of type B express the soluble guanylate cyclase Gucy1b2. Mol Cell Neurosci 65: 114-124.

Pacifico R, Dewan A, Cawley D, Guo C, Bozza T. 2012. An olfactory subsystem that mediates high-sensitivity detection of volatile amines. Cell Rep 2: 76-88.

Perez-Gomez A, Bleymehl K, Stein B, Pyrski M, Birnbaumer L, Munger SD, Leinders-Zufall T, Zufall F, Chamero P. 2015. Innate Predator Odor Aversion Driven by Parallel Olfactory Subsystems that Converge in the Ventromedial Hypothalamus. Curr Biol 25: 1340-1346.

Posadas-Andrews A, Roper TJ. 1983. Social transmission of food-preferences in adult rats. Animal Behavior 31: 265-271.

Ring G, Mezza RC, Schwob JE. 1997. Immunohistochemical identification of discrete subsets of rat olfactory neurons and the glomeruli that they innervate. J Comp Neurol 388: 415-434.

Roppolo D, Ribaud V, Jungo VP, Luscher C, Rodriguez I. 2006. Projection of the Gruneberg ganglion to the mouse olfactory bulb. Eur J Neurosci 23: 2887-2894.

Ross RS, Eichenbaum H. 2006. Dynamics of hippocampal and cortical activation during consolidation of a nonspatial memory. J Neurosci 26: 4852-4859.

Saraiva LR, Ibarra-Soria X, Khan M, Omura M, Scialdone A, Mombaerts P, Marioni JC, Logan DW. 2015. Hierarchical deconstruction of mouse olfactory sensory neurons: from whole mucosa to single-cell RNA-seq. Sci Rep 5: 18178.

Schmid A, Pyrski M, Biel M, Leinders-Zufall T, Zufall F. 2010. Grueneberg ganglion neurons are finely tuned cold sensors. J Neurosci 30: 7563-7568.

Shinoda K, Ohtsuki T, Nagano M, Okumura T. 1993. A possible functional necklace formed by placental antigen X-P2-immunoreactive and intensely acetylcholinesterase-reactive (PAX/IAE) glomerular complexes in the rat olfactory bulb. Brain Res 618: 160-166.

Shinoda K, Shiotani Y, Osawa Y. 1989. "Necklace olfactory glomeruli" form unique components of the rat primary olfactory system. J Comp Neurol 284: 362-373.

Storan MJ, Key B. 2006. Septal organ of Gruneberg is part of the olfactory system. J Comp Neurol 494: 834-844.

Sun L, Wang H, Hu J, Han J, Matsunami H, Luo M. 2009. Guanylyl cyclase-D in the olfactory CO2 neurons is activated by bicarbonate. Proc Natl Acad Sci U S A 106: 2041-2046.

Uytingco CR, Puche AC, Munger SD. 2016. Interglomerular Connectivity within the Canonical and GC-D/Necklace Olfactory Subsystems. PLoS ONE 11: e0165343. 
Walz A, Feinstein P, Khan M, Mombaerts P. 2007. Axonal wiring of guanylate cyclase-Dexpressing olfactory neurons is dependent on neuropilin 2 and semaphorin 3F. Development 134: 4063-4072.

Wang CY, Liu Z, Ng YH, Sudhof TC. 2020. A Synaptic Circuit Required for Acquisition but Not Recall of Social Transmission of Food Preference. Neuron 107: 144-157 e144.

Zheng LM, Ravel N, Jourdan F. 1987. Topography of centrifugal acetylcholinesterase-positive fibres in the olfactory bulb of the rat: evidence for original projections in atypical glomeruli. Neuroscience 23: 1083-1093.

Zimmerman AD, Munger SD. unpublished.

Zimmerman AD, Nagy CR, Munger SD. 2020. Sensory neurons expressing the atypical olfactory receptor guanylyl cyclase $D$ are required for the acquisition of odor preferences by mice in diverse social contexts. Physiol Behav 227: 113150. 